\title{
Ontogeny of Secretory Immunity: Levels of Secretory IgA and Natural Antibodies in Saliva
}

\author{
G. R. BURGIO. ${ }^{(2 M)}$ A. LANZAVEC(HIA. A. PLEBANI, S. JAYAKAR, AND A. G. UGAZIO \\ Department of Paediatrics and Department of Dermatologs: University of Pavia and the (NR Laboratory for \\ Biochemical and Evolutionary. (ienetics. Pavia. Italy.
}

\section{Summary}

In 187 healthy subjects from 2 months to 27 years of age, secretory IgA and free secretory component were assayed in samples of whole saliva obtained before and after stimulation with lemon juice. Antibody titers against Escherichia coli $O$ antigens and against rabbit erythrocytes were also dosed in unstimulated saliva. Secretory $\operatorname{IgA}$, undetectable in newborns, was present in all 2-month-olds tested in both unstimulated and stimulated saliva; thereafter secretory IgA levels increased progressively, reaching adult values by 6 to 8 years in unstimulated saliva and already by 2 to 4 years in stimulated saliva. The antibody titers assessed in unstimulated saliva followed a similar pattern also reaching adult values by 6 to 8 years. On the other hand, free secretory component levels showed no significant variation with age in unstimulated saliva whereas a slight increase was observed in the first year of life in stimulated saliva.

\section{Speculation}

The physiologic deficiency of SIgA and of secretory antibodies in infancy and childhood might well play a role in the pathogenesis of infectious diseases of the respiratory and gastrointestinal tract frequent in this age group.

The importance of the principal immunoglobulin of external secretions, secretory $\operatorname{IgA}(\mathrm{SIgA})$, in mucosal resistance to infection has been increasingly recognized $(3,10,21)$ : it occurs mainly as a dimer associated with a glycoprotein. the secretory component, which is synthesized by epithelial cells and attached to dimeric $\lg$ A during mucosal transfer $(14,21)$. Some secretory component does not interact with $\operatorname{IgA}$ and can be detected as free secretory component (FSC) in the secretion $(4,21)$.

Children with SIgA deficiency may be susceptible to severe infections of the respiratory and gastrointestinal tracts (1, 10): furthermore, there is some evidence that transient $\operatorname{IgA}$ deficiency in infancy results in an increased frequency of atopic disease (20).

SIgA is not detectable at birth, and the development of SIgA levels in infancy and childhood has heen the object of contradictory reports $(8,11,12,15,17,19)$. Assessment of SIgA levels has been hampered by its peculiar physicochemical properties, relatively low concentration. and dependence on secretory rate $(5,6$, 21).

Using an improved electroimmunodiffusion (EID) technique. we measured the concentrations of $\operatorname{SIgA}$ and FSC in samples of both unstimulated and stimulated saliva from 187 healthy subjects of different ages; in addition, in unstimulated saliva titers of antibodies against different serotypes of Escherichia coli and rabbit red blood cells ( $R a R B C$ ) were assessed. Our results show that concentrations of SIgA and secretory antibodies increase gradually during infancy and childhood and attain adult levels in unstimulated saliva only at about the age of 6 to 8 years.
MATERIALS AND METHODS

SUBJE(TS AND SAMPI.ES

Samples of whole saliva were collected from 187 healthy subjects (26) ranging in age from 2 months to 27 years using soft plastic tubing connected to a disposable syringe. Stimulated saliva was obtained $3 \mathrm{~min}$ after local stimulation with lemon juice Samples were centrifuged at $4000 \times g$ for $30 \mathrm{~min}$ at $4^{\circ} \mathrm{C}$, and the clear supernatant was stored at $-30^{\circ} \mathrm{C}$ until tested. Controls revealed no significant decrease of SIgA, FSC, or antibody activity after a 3-month storage period.

\section{QUANTITATON OF SIgA}

SIgA was quantitated by EID as described by Schüller $e t$ al. (16) with slight modifications. The buffer used for migration and gel plates was a $0.03 \mathrm{M}$ barbitone buffer containing $0.09 \mathrm{M}$ Tris and calcium lactate $(0.13 \mathrm{~g}$ /liter: $\mathrm{pH} 8.6 ; \mu=0.02)$. One "; agarose plates (Behringwerke) were prepared containing $0.8 \%$ rabbit antihuman $\operatorname{IgA}$ (Behringwerke) and $0.4 \%$ carboxyethylcellulose ( $\mathrm{Ty}$ lose. Hoechst) to increase the anodal mobility of SIgA. Plates were run at $10 \mathrm{~V} / \mathrm{cm}$ for $5 \mathrm{hr}$ washed, dried, and stained with Coomassie brilliant blue.

The dose-response curves of two-fold dilutions of serum. saliva. and colostrum were parallel, indicating a constant relationship between serum and secretory $\operatorname{IgA}$ so a working standard serum was calibrated with reference to a preparation of purified dimeric IgA and used throughout the study. Precipitates of the same size were produced at SIgA concentrations 2.3 times that of serum $\lg \mathrm{A}$ : all concentrations were therefore expressed in $\mathrm{mg} / 100 \mathrm{ml}$ of SIgA.

Height of the peaks was modified by the presence of only more than $20 \%$ monomeric $\operatorname{IgA}$ as also reported with the Mancini technique (13), a value usually not exceeded in normal secretions (21)

To control for major contamination with serum proteins and thus $\operatorname{lgA}$, albumin concentration was measured in all samples of unstimulated saliva by EID using a rabbit antialbumin antiserum (Behringwerke) in 1 marose plates. Albumin was present in low concentrations (mean $4.6 \mathrm{mg} / 100 \mathrm{ml} \pm 0.6 \mathrm{~S}$. E.) except in rare samples containing more than $10 \mathrm{mg} / 100 \mathrm{ml}$ which were excluded from the study.

\section{QUANTITATION OF FSC}

FSC was also quantitated using EID under the same conditions described for SIgA except that the specific antiserum (Behringwerke) was used in a concentration of $2 \%$. To check antiserum specificity, the fractions of normal human colostrum obtained by gel filtration on Sephadex G-200 were tested by EID; the antiserum reacted only with those fractions eluted at a volume corresponding to the molecular weight of FSC: addition of large 
amounts of purified SIgA had no effect on the quantitation of FSC. Inasmuch as no standard for FSC was available, all the values were expressed as arbitrary units with reference to a colostral pool.

\section{SEC RETORY ANTIBODIES AGAINST $E$. COLI O ANTIGENS}

Secretory antibodies against $E$. coli $\mathrm{O}$ antigens of six "common" serotypes (27) (01.KI.H7., 02.KI.H4, 04.K3.H5, 06.K2 ac.HI. 015.K 14.H4, and 075.K.H5.) were assayed by passive hemagglutination as described elsewhere with slight modifications (22. 24. 25).

Briefly. $100 \mu \mathrm{l}$ of washed packed group 0 human erythrocytes were sensitized with $1 \mathrm{ml}$ of a pool of the six antigens at $37^{\circ} \mathrm{C}$ for $20 \mathrm{~min}$, washed three times, and resuspended at a $1 \%$ c concentration in saline. Two-fold dilutions of the samples of unstimulated saliva were set up in saline buffered with $0.01 \mathrm{M}$ Tris $(\mathrm{pH} 7.5)$ containing $0.1 \%$ bovine serum albumin in $50 \mu$ volumes in $U$ bottomed microtiter plates: $50 \mu \mathrm{l}$ of $1 \%$ sensitized red cells were added and agglutination was read after $2 \mathrm{hr}$ incubation at $37^{\circ} \mathrm{C}$. Controls with unsensitized human red blood cells were always negative.

\section{SECRETORY ANTIBODIES TO RaRBC}

Two-fold dilutions of saliva were set up as described for $E$. coli antibodies, and $50 \mu \mathrm{l}$ of a $0.75 \%$ suspension of RaRBC were added. Plates were incubated at room temperature for $4 \mathrm{hr}$. Absorption experiments showed that there was no cross-reactivity between $E$. coli and $\mathrm{RaRBC}$ antibodies either in serum or in saliva.

Titers of $E$. coli and RaRBC antibodies were assessed in the same samples used for quantitation of $\operatorname{SIgA}$; because major contamination of these samples with serum proteins was ruled out (see before), the titers measured were assumed to represent secretory antibody activity.

\section{STATISTIC AL EVALUATION}

The subjects were divided into 10 age groups ( 2 to $4 \mathrm{mo}, n=$ 14: $>4$ to $6 \mathrm{mo}, n=22 ;>6$ to $12 \mathrm{mo}, n=14:>12$ to $24 \mathrm{mo}, n=$ 24: $>2$ to 4 yr, $n=22 ;>4$ to 6 yr, $n=14 ;>0$ to 8 yr, $n=12 ;>8$ to $10 \mathrm{yr}, n=24:>10$ to $12 \mathrm{yr}, n=14:>12 \mathrm{yr}, n=27$ ). The mean value for each group is reported in the figures in correspondence to the mean age of each group. All data were transformed into logarithms before analysis to achieve a normal distribution. The graphs are also drawn on a logarithmic scale. For differences between groups, the Student $t$ test was used, and a 3-way analysis of variance was used to test for differences between subjects. days on which they were tested. and morning and afternoon of the same day.

\section{RESULTS}

\section{BFFEC T OF STIMULATION ON SIgA AND FSC CONCENTRATIONS IN SALIVA}

In preliminary experiments, samples of saliva were obtained before and at different times after local stimulation with lemon juice in a group of 10 healthy children. Stimulation resulted in a prompt sharp decrease in the concentrations of both SIgA and FSC which persisted over the next 10 to $15 \mathrm{~min}$. The ratio. SIgA/ FSC, also decreased after stimulation and showed great individual variability. Inasmuch as stimulation markedly increases salivary flow rate (5). SIgA concentration in stimulated saliva can be considered an index of the capacity of the secretory immune system to counterbalance physiologic increases in secretory rate.

\section{LONGIITUDINAL. VARIABILITY OF SIgA}

To obtain information on the variability of SIgA levels in time, samples of stimulated and unstimulated saliva were collected in 5 subjects in the morning and afternoon of 3 days over a period of
30 days. As evident from statistical analysis of the data on unstimulated saliva presented in Table 1, variability between subjects was highly significant and much greater than that within or between days. Similar results were also obtained with stimulated saliva.

\section{DEVELOPMENT OF SIgA AND FSC}

SIgA was undetectable $(<0.2 \mathrm{mg} \%)$ in 10 of 10 newborns, but was detectable in all the 2 month olds tested: however, the mean concentration both in unstimulated and stimulated saliva was significantly lower than in adults. Figure 1 shows that $\operatorname{SIgA}$ increased slowly in the course of infancy and childhood; adult values were reached in the 6- to 8-year age group in unstimulated saliva, whereas in stimulated saliva, they were already attained in the 2 to 4-year age group. The slight decrease in SIgA levels observed from 3 to 5 months both in unstimulated and stimulated saliva is not statistically significant.

As seen from Figure 2. FSC concentrations showed minimal

Table 1. Longitudinal variability of SIgA levels (mg 'i) in

\begin{tabular}{|c|c|c|c|c|c|c|c|c|}
\hline \multirow{4}{*}{ Subject } & \multirow{4}{*}{$\begin{array}{l}\text { Age } \\
(\mathrm{yr})\end{array}$} & \multirow{2}{*}{\multicolumn{6}{|c|}{$\begin{array}{r}\text { Day } \\
\text { Dastimulea }\end{array}$}} & \\
\hline & & & & & & & & \multirow{3}{*}{$\begin{array}{c}\text { Mean } \\
\text { (geometric) }\end{array}$} \\
\hline & & \multicolumn{2}{|c|}{1} & \multicolumn{2}{|c|}{15} & \multicolumn{2}{|c|}{30} & \\
\hline & & $\mathrm{AM}$ & $\mathrm{PM}$ & $\mathrm{AM}$ & PM & $\mathrm{AM}$ & PM & \\
\hline A & 25 & 11.5 & 10.0 & 11.5 & 10.0 & 6.0 & 9.0 & 9.46 \\
\hline B & 24 & 23.5 & 14.0 & 17.0 & 15.0 & 21.0 & 17.0 & 17.61 \\
\hline c & 5 & 8.5 & 5.0 & 6.5 & 8.5 & 6.5 & 7.5 & 6.91 \\
\hline I) & 5 & 9.5 & 9.5 & 8.5 & 8.0 & 6.5 & 9.0 & 8.43 \\
\hline$E$ & 3 & 4.5 & 2.5 & 5.0 & 4.0 & 6.0 & 2.5 & 3.87 \\
\hline
\end{tabular}

Analysis of Variance

Between subjects

Between days

Within days

$30.7<0.001$

$0.5 \quad$ N.S.'

'N.S.. not significant.

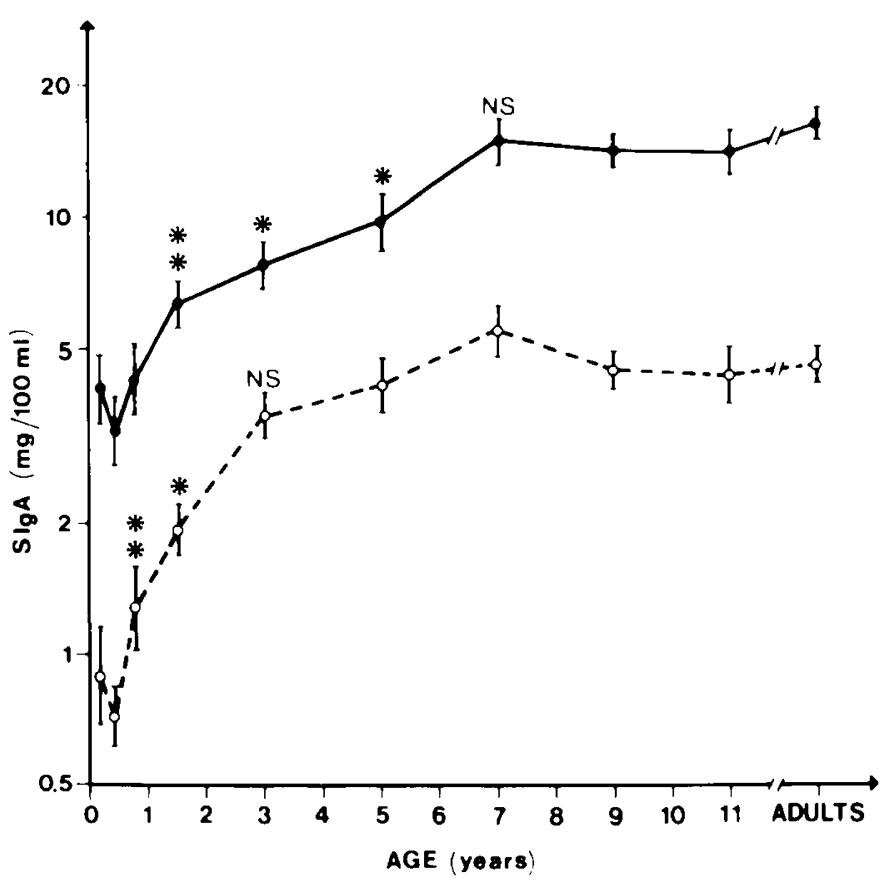

Fig. I. Concentrations of SIgA at different ages in unstimulated (O) and stimulated (O) saliva. The geometric mean for each age group is plotted \pm 1 standard error. Significance of the difference between adult values and each age group is also reported. N.S., not significant: ${ }^{*}, P<$ $0.05: * * . P<0.001$. 


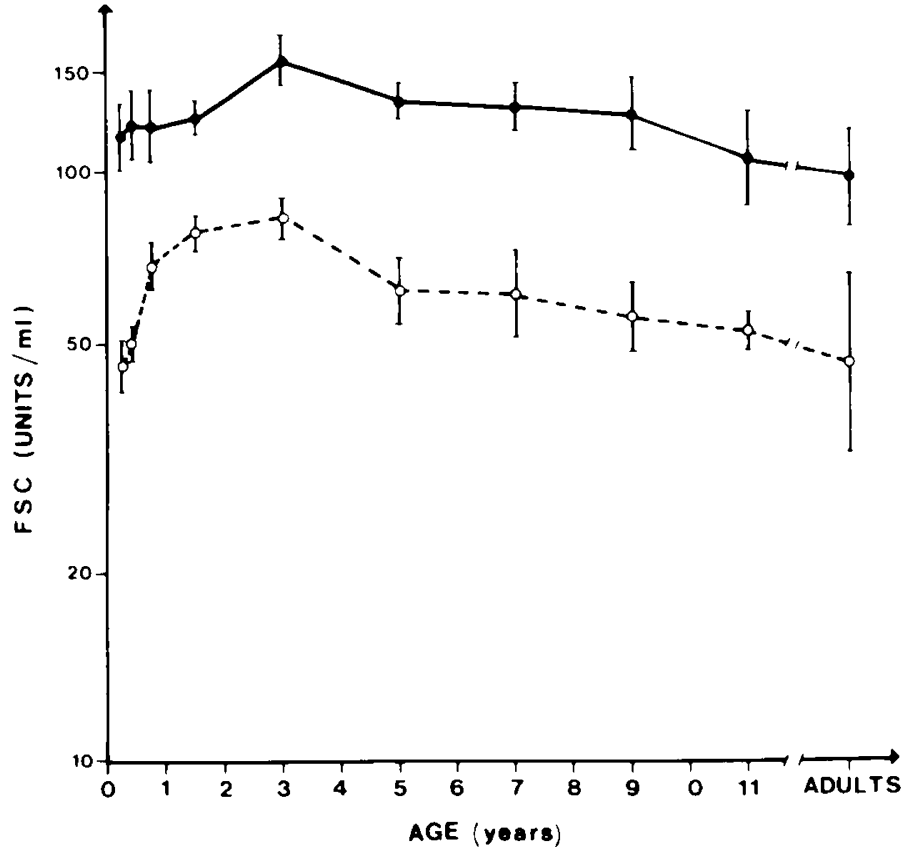

Fig. 2. Concentrations of FSC at different ages in unstimulated (-) and stimulated $(O)$ saliva. The geometric mean for each group is plotted \pm 1 standard error.

variation with age in unstimulated saliva although in stimulated saliva an increase was seen in the first year of life. After 3 years of age, a decrease in FSC concentrations was evident both in stimulated and unstimulated saliva, but significance was not reached because of the variability of FSC concentrations.

\section{DEVELOPMENT OF SECRETORY ANTIBODIES}

Figures 3 and 4 show the variation with age of the titers of secretory antibodies directed against $E$. coli $\mathrm{O}$ antigens and against $\mathrm{RaRBC}$ in unstimulated saliva. The pattern of the antibody titers with age was similar to that of SIgA levels in unstimulated saliva. and adult levels were also reached in the 6- to 8-year age group.

\section{DISCUSSION}

Preliminary experiments showed that although whole saliva is a complex mixture of different secretions and is subject to uncontrollable variations in flow rate $(5,6,21)$, it may be an adequate sample for studying secretory immunity. In fact, interindividual variability of SIgA levels far exceeded intraindividual variabilit; on repeated assessments over a period of time, a finding that clearly indicates the biologic significance of SIgA levels in saliva.

The simultaneous assessment of SIgA and albumin used in this study allows exclusion of significant contamination with serum $\operatorname{IgA}$, so this system compares favorably with more sophisticated techniques allowing direct estimation of $\operatorname{SIgA}(18,23)$.

The ontogenetic study shows that SIgA, absent at birth, become detectable in the saliva of healthy infants by the age of two months and thereafter undergo a progressive increase with age to attain adult values at about 6 to 8 years in unstimulated saliva and already at 2 to 4 years in stimulated saliva.

We have no simple explanation for the finding that adult levels of SIgA are attained earlier in stimulated saliva; indeed, it is tempting to speculate that the capacity to maintain relatively high levels of SIgA under condition of high flow rate is of biologic importance in the defense against infections and is therefore acquired earlier in the course of ontogeny. However, the similar time course of SIgA levels in both unstimulated and stimulated saliva clearly shows that the mean concentration of $\operatorname{SIgA}$ is significantly lower in infants and children than in adults whatever the systematic variation of physiologic secretory rate with age.
The present findings are substantially in agreement with the report of Savilahti (15) that $\operatorname{SIgA}$ levels in the intestinal juice and number of IgA plasma cells in the intestinal submucosa are consistently lower under 2 years of age than afterwards and also with the report of South et al. (19) stating (although not providing data) that salivary $\lg A$ has a slow pattern of maturation similar to that of serum $\operatorname{IgA}$. However in other studies, some of which published more than 10 years ago, "adult" levels of SIgA are

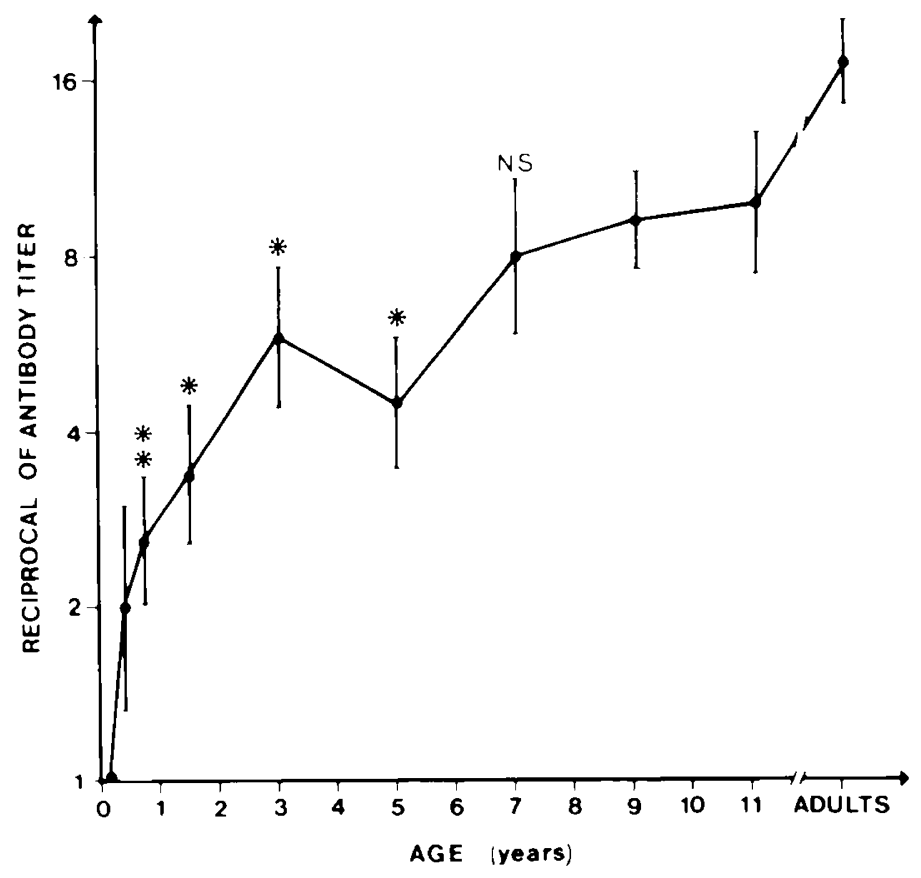

Fig. 3. Antibody titers against $E$. coli $\mathrm{O}$ antigens at different ages in unstimulated saliva. The geometric mean for each age group is plotted $\pm I$ standard error. Significance of the difference between adult values and each age group is also reported. N.S., not significant: ${ }^{*}, P<0.05,{ }^{* *}, P<$ 0.001 .

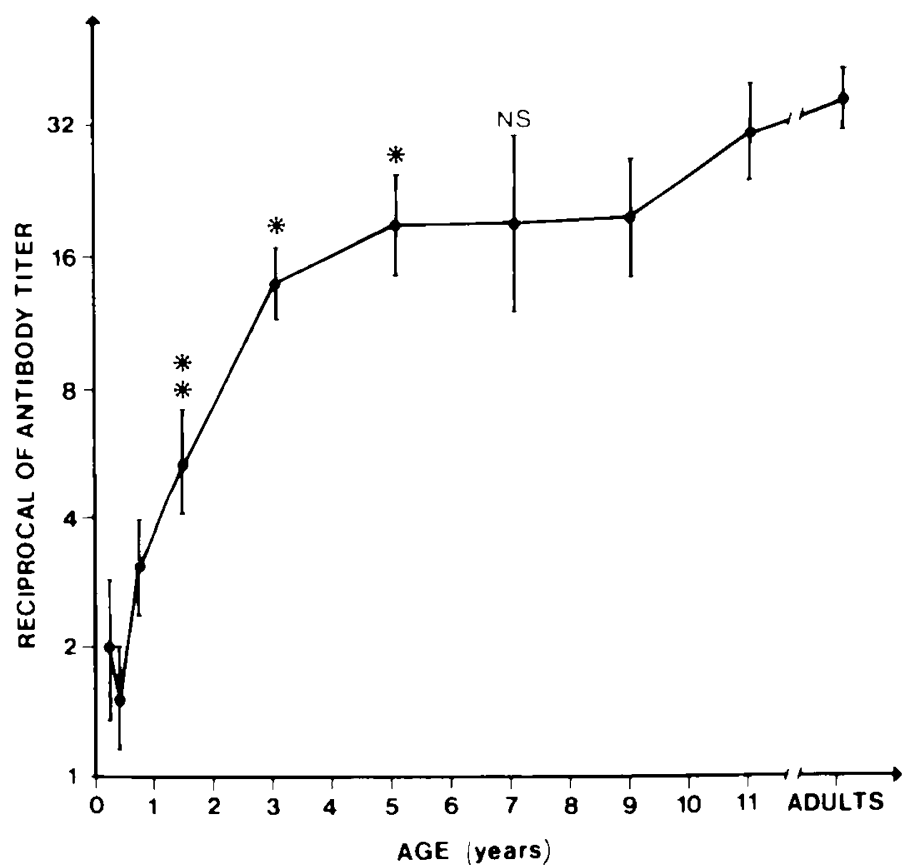

Fig. 4. Antibody titers against RaRBC in unstimulated saliva. The geometric mean for each age group is plotted \pm 1 standard error. Significance of the difference between adult values and each age group is also reported. N.S., not significant: ${ }^{*}, P<0.05 ;{ }^{* *}, P<0.001$. 
reported to be attained in various secretions much earlier, usually during the first few months of life $(8,11,12,17)$. This discrepancy might be explained, at least in part, by differences in the techniques used for the quantitation of SIgA: indeed, such techniques have undergone great improvement during recent years $(2,16)$. In addition, one must point out that comparison between results obtained in different secretions may be misleading because the degree of antigenic stimulation and the homing of lymphocytes may vary during the ontogenesis from one secretory site to another.

In the present study we also assessed simultaneously two noncross-reacting antibodies which showed age-dependent variations similar to that of SIgA. thus further supporting the concept of a gradual maturation of the secretory immune system in saliva. Our data, showing very low levels of $E$. coli antibodies in unstimulated saliva during the first year of life provide further, although indirect, evidence for the protective role of such antibodies present in very high concentrations in human milk (9).

The difference in the time course of FSC, which is present in adult amounts already in the first few months of life is further evidence of the biologic significance of the increase observed in SIgA and secretory antibody concentrations. With regard to FSC, the finding of adult levels in unstimulated saliva early in ontogeny is in keeping with the observation that secretory component appears well before $\operatorname{SIgA}$ is first synthesized (14). One might speculate that the slight decrease in FSC levels evident after 3 years in both unstimulated and stimulated saliva could reflect an increased binding to SIgA; changes in FSC levels might occur as a result of changes in percentage bound (4), but would be quite difficult to demonstrate because of the relatively small proportion of bound secretory component and of the high variability of FSC levels. Indeed, in 4 patients lacking SIgA, levels of FSC were high. but not significantly different than in age-matched controls (data not shown).

On the whole, the data of this study show that the assessment of SIgA and of secretory antibodies may be a useful tool not only for the study of the ontogeny of the secretory immune system but also for the study of immunodeficiency diseases such as selective IgA deficiency or other types of defects of secretory immunity, for example those implicated in atopic diseases $(7,20)$.

\section{REFERENCES AND NOTES}

1. Amman. A. J., and Hong. R.: Selective IgA deficiency. In: E. R. Stiehm. V. A Fulginiti: Immunological disorders in Infants and (hildren. p. 199 (W. B Saunders (O., 1973).

2. Axelsen. N. H., Krøll, J., and Weeke, B.: Quantitative immunoelectrophoresis Scand. J. Immunol. Suppl., I: 2 (1973).

3. Bellanti. J. A.. Artenstein. M. S., and Buescher. E. L.: Characterization of virus neutralizing antibodies in serum and nasal secretions. J. Immunol.. 94: 344 (1965).

4. Brandtzaeg. P.: Human secretory immunoglobulins. IV. Quantitation of free secretory piece. Acta Pathol. Microbiol. Scand. Sect. B Microbiol. Immunol.. 79: $189(1971)$
5. Brandtzaeg. P.: Human secretory immunoglobulins. VII. Concentrations of parotid IgA and other secretory proteins in relation to the rate of flow and duration of secretory stimulus. Arch. Oral Biol., /6: 1295 (1971).

6. Brandtzaeg. P.. Fjellanger. I., and Gjeruldsen. S. T.: Human secretory immunoglobulins. I. Salivary secretions from individuals with normal or low levels of serum immunoglobulins. Scand. J. Haematol. Suppl.. I2: I (1970).

7. Burgio, G. R.. Nespoli, L., and Ugazio, A. (i.: Atopy as a minimal immunodeficiency". Eur. J. Pediatr.. 120:221 (1978).

$x$. Haneberg. B. and Tonder. O: Immunoglobulins and other serum proteins in feces from infants and children. Scand. J. Immunol. 2: 375 (1973).

9. Hanson. L. A.. Ahlstedt. S.. Carlsson. B.. Fallstrom. S. P.. Kaijser. B.. Lindhlad. B. S. Akerlund. A. S., and Eden. ( . S.: New knowledge in human milk immunoglohulin. Acta Paediatr. Scand.. o?: 577 (1978)

10. Hanson. L.. A... and Brandtzaeg. P.: Secretory antibody systems. In: E. R. Stuehm. V. A. Fulginiti: Immunological disorders in infants and children. p. 107 (W. B. Saunders (o.. 1973).

11. Haworth. J. (... and Dilling. L.: Concentration of $\gamma$ A-globulin in serum. saliva. and nasopharyngeal secretions of infants and children. J. L.ab. Clin. Med.. $A$ ? 922 (1966).

12. McKay. E.. and Thom. H.: Observations on neonatal tears. J. Pediatr., ${ }^{-5 .}$ 1245 (1969).

13. Newcomb. R. W.. and De Wald. B.: Protein concentrations in sputa from asthmatic children: albumin. lactoferrin, $\gamma \mathrm{A}$ and $\gamma(\mathrm{j}$. J. Lab. (lin. Med.. ?3: 734 (1969).

14. Ogra, S. S.. Ogra, P. L.. Lippes, J., and Tomasi, T. B.: Immunohistologic Iocalization of immunoglobulins. secretory component and lactoferrin in the developing human fetus. Proc. Soc. Exp. Biol. Med.. 139: 570 (1972).

15. Savilahti. E.: Immunoglobulin-containing cells in the intestinal mucosa and immunoglobulin in the intestinal juice in children. Clin. Exp. Inmunol.. $/ 1$ : $415(1972)$.

16. Schuller. E.. Lefevre. M.. and Tömpe, L.: Electroimmunodiffusion of a:M. Ig.A and $\lg M$ in nanogram quantities with a hydroxyathylcellulosa-agarose gels: application to unconcentrated (SF. ( lin. Chim Acta, 42: 5(1972).

17. Selner. J. C.. Merrill. D. A.. and (laman. N. H.: Salivary immunoglobulin and alhumin: development during the neonatal period. J. Pediatr. $2: 685$ (1968)

1x. Sohl Akerlund A., Hanson L. A.. Ahlstedt S.. and (arlsson B. A sensitive method for specitic quantitation of secretory IgA. Scand. J. Immunol.. 0. 1275 (1977).

19. South. M. A.. Warwick. W. J., Wollheim. F. A.. and ciood. R. A.: The $\lg A$ system. III. IgA levels in the serum and saliva of pediatric patients evidence for a local immunological system. J. Pediatr. 7/: 645 (1967)

20. Taylor. B., Norman. A. P., Orgel. H. A.. Stokes. (. R.. Turner. M. W.. and Soothill, J. F.: Transient IgA deficiency and pathogenesis of infantile atopy Lancet. ?: I) (1973).

21. Tomasi. T. B.. and (irey. H. M.: Structure and function of immunoglobulin A Prog. Allergy. 16: 81 (1972)

22. Tonder. $O$.. and Larsen. B.: Agglutinins in humans saliva to rabbit ervthrocvles Vox Sang.. 24: 515 (1973).

23. Uehling. D.. and Hong. R.: Quantitation of urinary immunoglublins hy a double antibedy lechnuye Invest. Urol. 15:39) (1977)

24. Ugazio, A. G.. Lanzavecchia. A., Jayakar. S.. Plebani. A., Duse. M., and Burgio, G. R.: Immunodeficiency in Down s syndrome: titres of natural antibodies 10 E. coli and rabbit erythrocytes at different ages. Acta Paediatr. Scand.. 6 ? : 705 $(1978)$.

25. Webster, A. D. B., Efter. T., and Asherson. (;. L.: Escherichia coli antibody: a screening test for immunodeficiency. Br. Med. J.. 3: 16 (1974)

26. Informed consent was obtained from all parents and adult subjects in accordance with Italian requirements for clinical studies.

27. The authors thank Dr. A. D. B. Webster, Clinical Research Centre, Harrow, England for kindly supplying the $E$ : coli $O$ antigens.

28. Requests for reprints should be addressed to: Professor (j. R. Burgio, Departmen of Paediatrics. University of Pavia. 27 I00 Pavia. Italy.

29. This research was supported in part by Consiglio Nazionale Ricerche. Roma.

30. Received for publication July 26, 1979

31. Accepted for publication January 4. 1980. 